\title{
Método fisicoquímico para el control de Pediculus humanus capitis
}

\author{
Corredor C. ${ }^{1}$, Ruiz C.H. ${ }^{2}$, Castro L.M. ${ }^{2}$
}

\begin{abstract}
RESUMEN
La pediculosis humana causada por el ectoparásito Pediculus humanus capitis, ha sido exitosamente controlada utilizando como insecticida los alcoholes presentes en las bebidas etílicas (aguardiente). La acción ietal de los alcoholes de bebida sobre el parásito es atribuida al efecto neurotóxico, así como a su acción desnaturalizante de biomoléculas celulares. El tratamiento se hace cubriendo el cabello y todas las áreas del cuero cabelludo con una bolsa plástica desechable, fijada con cinta adhesiva, previo remojo con $15-50 \mathrm{ml}$ de alcohol de bebida, de todo el cabello. La atmósfera circundante del parásito queda saturada de vapores etílicos, de agua y CO2, por un período de 30-60 minutos, lo cual es letal para huevos, larvas y adultos del insecto parásito. Se dan normas cautelosas para garantizar la acción insecticida de los alcoholes de bebida en el control de la pediculosis.
\end{abstract}

\begin{abstract}
SUMMARY
Pediculus humanus capitis was controled in humans using ethanol containing beverages. Organic solvent and destabilizer membrane properties of these alcohols are the main causes of insect death. Effective control was achieved using 15 or $50 \mathrm{ml}$ of fire-water, (aguardiente), evenly disiributed on the scalp. A disposable plastic bag properly closed around the scalp for only 20-30 minutes provides a letal saturated atmosphere with alcohol water and $\mathrm{CO} 2$ around the adult, larve and eggs of the insect. Some guidelines are suggested to ensure that optimum control is achieved.
\end{abstract}

La pediculosis humana, especialmente en los hacinamientos, es todavía uno de los problemas de salud comunitaria aún no resuelto a pesar de las campañas de higiene puestas en marcha (13) y de los conocimientos biológicos sobre el parásito, figura 1, (4-7). El P. humanus capitis es una especie de insecto del orden Anoplura que habita en ecosistemas de climas fríos, montañosos preferencialmente.

1 Profesor asociado, Facultad de Odontologia, en comisión en la Facultad de Medicina, Universidad Nacional de Colombia

2 Facultad de Enfermería, Universidad Nacional, Bogotá
Con el uso de plaguicidas se ha logrado un control temporal de las especies $P$. humanus corporis y $P$. humanus capitis, $(3,5,6)$, pero dado el riesgo inherente en la aplicación de productos químicos directamente a la piel humana y los mecanismos de defensa del parásito, no se ha logrado un control satisfactorio (8). Lo que es tóxico y letal para el insecto parásito, también lo es en alguna forma para las células o tejidos expuestos del hospedero. No se ha encontrado un insecticida que dentro de las dosis farmacológicas utilizadas haya demostrado ser inocuo para el hospedero (9). Estos pueden causarle en mayor o menor grado trastornos fisiológicos o genéticos (10-13), o causar desastres ecológicos cuando se generaliza su uso (14). 


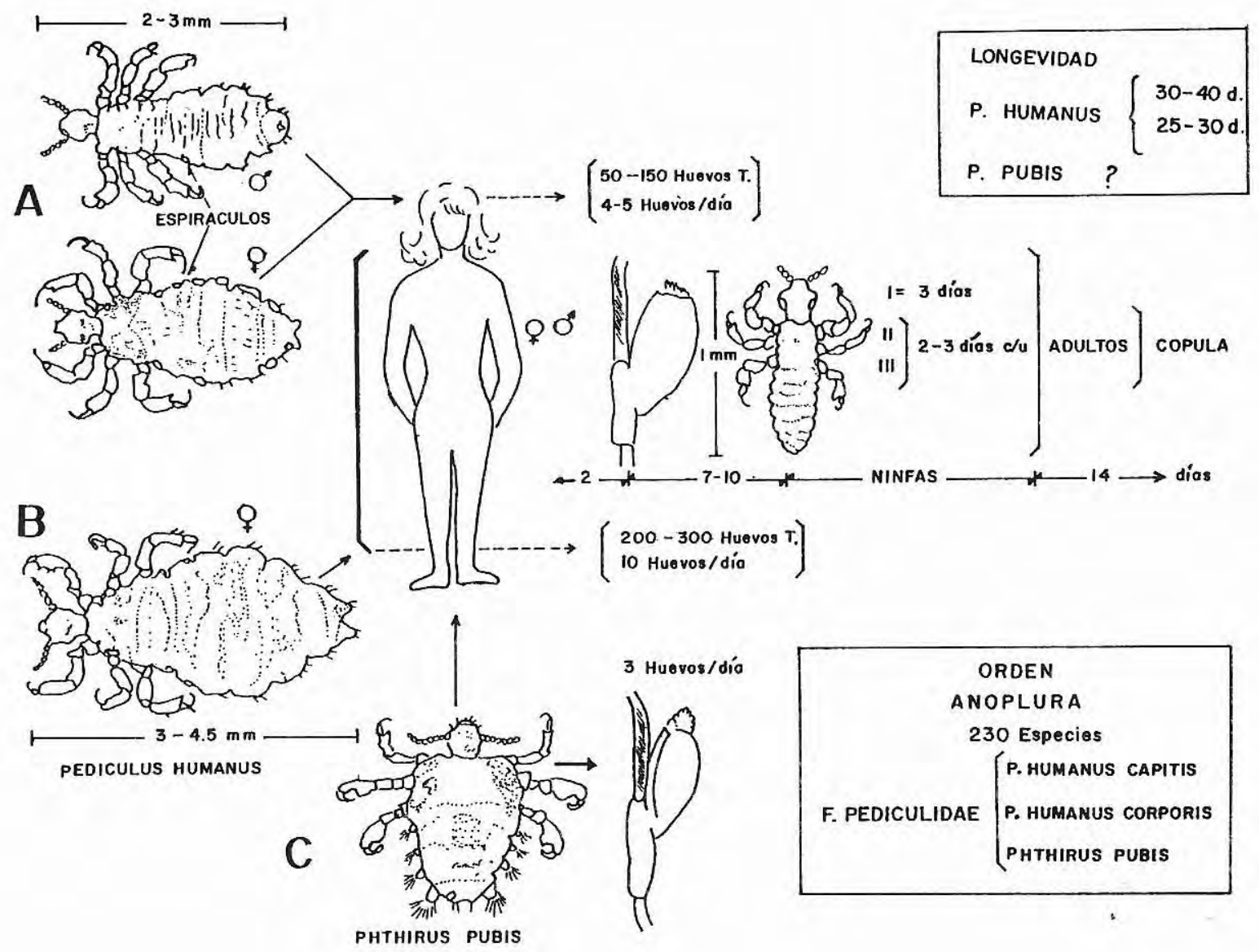

figura 1. Características biológicas de las tres especies apterigotas (orden Anoplura), hematófagas, vectores de varias enfermedades infectocontagiosas en humanos. A) $P$. humanus capitis. Nótese que la hembra es más grande que el macho. Al reproducirse producen unos 50 a 150 huevos/hembra y poseen una longevidad entre entre $30-40$ días. B) $P$. humanus corporis, al reproducirse son más prolíficos ya que pueden producir unos 200-300 huevos /hembra, con una longevidad de 25-30 días. El ciclo de vida de estas dos especies es muy similar y puede durar unos 14 días. Estos ectopárasitos atacan indiscriminadamente tanto al citadino como al campesino (climas fríos, montañosos). C) Pthirus pubis, tiene una ovoposición de sólo unos 3 huevos por día y ataca las zonas genitales púbicas. Prevalece en climas templados y cálidos preferencialmente $(1,4-6)$.

Para el control de la pediculosis en humanos o en animales domésticos se han utilizado repelentes o insecticidas como aceite de olivas, petróleo o sus derivados, alcoholes alcanforados, vinagre fenicado (15), benzoato de benzilo, organoclorados, organofosforados, carbamatos o piretroides $(5,7,8)$, etc., cuya inocuidad toxicológica no ha sido demostrada.

Una alternativa para el control de la pediculosis en humanos es la de utilizar productos químicos de uso generalizado como bebidas y combinarlos con técnicas físicas que afectan diferencialmente a la fisiología del parásito. Entre los productos de amplio uso por el hombre y cuya inocuidad relativa ha sido aceptada, se encuentran las bebidas alcohólicas, de las cuales no se había reportado su poder insecticida. Norris y Parker en1969, usaron el etanol como estimulante del apetito de larvas de Xileborus ferrugineus (16). C.H. Ruiz de Cárdenas, L.M. Castro de 
Rubiano y C. Corredor, en un estudio sobre los efectos psicomotrices de la aplicación tópica de bebidas alcohólicas en dosis únicas, en adolescentes, demostraron la ausencia de efectos tóxicos colaterales (Facultad de Enfermería, Universidad Nacional, 1986).

Los efectos biológicos de los componentes alcohólicos de estas bebidas y, en especial del etanol, no han demostrado ser letales cuando se ingieren en dosis únicas moderadas, dosis que pueden ser aprovechadas para controlar ectoparásitos tanto en el hombre como en animales domésticos. Sin embargo, su uso generalizado en humanos debe restringirse por razones éticas (17) y por el riesgo toxicológico inherente a toda sustancia química $(3,9)$.

El etanol y en general los alcoholes, poseen tres propiedades fisicoquímicas muy importantes que podrían alterar la fisiología de los insectos parásitos: su velocidad de evaporación comparada con las sustancias humorales, su capacidad como solvente orgánico y su acción desnaturalizante sobre algunas proteínas que forman parte de las membranas celulares (18-20-27) o cuticulares; son propiedades fisicoquímicas que en conjunto podrían ser letales para el ectoparásito, en forma análoga a como han demostrado serlo para otros sistemas biológicos (21-27).

\section{Materiales y métodos}

Aguardiente, grado alcohólico entre 30-35 grados: 15 a $50 \mathrm{ml}$ para cada persona. Un pañuelo, tela o algodón. Una bolsa de plástico desechable tan grande que se pueda usar como sombrero. Cinta pegante. Un recipiente para lavarse la cabeza. Agua tibia. Microscopio estercoscópico con epiiluminación.

La población humana tratada fueron voluntarios (2 adultos, 18 niños) los cuales presentaban parasitismo de moderado a alto (tabla 1). Algunos de los niños asistían a la escuela de la vereda La Balsa, Chía, Cundinamarca.

Se humedeció abundantemente toda la cabellera con el alcohol de bebida (15 a $50 \mathrm{ml}$ de aguardiente por persona) asegurándose que la nuca y las patillas quedasen bien empapadas. Inmediatamente se colocó la bolsa de plástico
Tabla 1. Control fisicoquímico del Pediculus humanus capitis, en una población humana en la sabana de Bogota; $\mathrm{T}: 11^{\circ} \mathrm{C}, 2.500 \mathrm{msnm}$, Colombia, Corredor 1983.

\begin{tabular}{cclrrr} 
Sexo & \multicolumn{2}{c}{$\begin{array}{c}\text { Edad Parasitismo } \\
\text { años }\end{array}$} & (1) & Tratados & $\begin{array}{c}\text { Eficiencia Fecha } \\
\%\end{array}$ \\
\hline F & $30-40$ & Moderado & 1 & 100 & feb/83 \\
M & $41-50$ & Moderado & 1 & 100 & feb $/ 83$ \\
M & $3-5$ & Alto & 10 & 98 & nov $/ 83$ \\
M & $6-10$ & Moderado & 3 & 100 & nov/83 \\
F & $6-10$ & Alto & 5 & 100 & feb/84 \\
\hline
\end{tabular}

(1)Parasitismo arbitrario. Moderado: menos de dos ejemplares adultos por decímetro cuadrado. Alto: más de dos ejemplares adultos por decímetro cuadrado y presencia de huevos abundantes en los cabellos. Las personas tratadas no presentaban eritemas ni heridas asociadas al parasitismo.

sobre la cabeza cubriendo todo el cuero cabelludo y la cabellera, procurando ajustar los bordes de la bolsa con una ligadura o con la cinta pegante, asegurando que en lo posible no hubiese escape de vapor, durante aproximadamente 30 - 60 minutos. Esto es importante ya que el aguardiente debe ir calentándose con el calor del cuero cabelludo para que sea efectivo. En algunos casos se aprovechó el calor solar para facilitar la evaporación del alcohol de bebida. Se cuidó de no mojar la frente y se evitó que el aguardiente llegara hasta los ojos. Finalmente, se removió el plástico de la cabeza y si el tiempo lo permitía, se lavó el cuero cabelludo. con agua tibia abundante.

\section{Resultados y discusión}

La saturación atmosférica con vapores de alcohol de bebidas y agua, alrededor de donde habita el parásito, por un tiempo mayor de 30 minutos, hace que el insecto adulto cierre sus espiráculos como defensa, pero, al cabo de varios minutos el insecto nuevamente los debe abrir $(7,28)$, facilitando la entrada de dosis letales de vapor de alcohol a su organismo. La acción letal del alcohol de bebida sobre la fisiología del adulto, $P$. humanus capitis, ya sea por contacto o por inhalación, le produce una hipercinesia errática, irritabilidad sensorial, característica de los sustancias que interfieren los sistemas nerviosos tanto central como periférico y ganglionar. A esta ac- 
ción letal se le suma la anoxia causada por el encerramiento de la bolsa plástica. Posteriormente, la acción narcótica le impide al insecto adulto desplazarse localmente y termina por permanecer inmóvil, presentando reflejos incoordinados abdominales o de las extremidades anteriores y de las antenas.

Al observar bajo el microscopio ejemplares tratados, se encontró que los reflejos de extremidades anteriores y antenas aún perduran por espacio de 5 a 8 horas. En la tabla 1 se observa que en la mayoría de las personas tratadas se obtuvo una eliminación total del parásito.

El etanol, una vez entra en contacto con la piel del cuero cabelludo, por el calor de éste se convierte rápido en vapor. Esta distribución en forma de vapor asegura su acción letal, aún en aquellos sitios del cuero cabelludo o de los cabellos que no permiten la entrada en forma líquida, ya que forma una atmósfera circundante con vapores de alcohol, facilitando la penetración del etanol al cuerpo del insecto adulto. La acción letal sobre los huevos o estados embrionarios inmóviles podría ser también a través de la difusión fisicoquímica del etanol, desnaturalizando irreversiblemente ciertas enzimas celulares del parásito. Además, la saturación de la atmósfera con vapores etílicos y acuosos junto con el $\mathrm{CO} 2$ de la respiración de la piel, propicia una anoxia relativa, que acelera el efecto letal del tratamiento inhabilitando al parásito para buscar alimento.

Es muy importante asegurar el cubrimiento total del cabello y cuero cabelludo por el tiempo estipulado. Tratamientos incompletos o parciales con bebidas etanólicas diluídas, favorecerían la prevalencia y reinfestación por el ectoparásito. Además, las aplicaciones cortas o breves, aunque repetidas, podrían inducir resistencia o tolerancia del parásito al etanol, en forma análoga a la tolerancia a organoclorados (8).

En las condiciones del presente experimento se ha logrado una efectividad del cien por ciento (tabla 1). No obstante, una reinfestación es posible ya que $P$. humanus capitis puede vivir temporalmente en la ropa, sitios de descanso o de trabajo, al igual que la especie $P$. humanus corporis con el cual se cree que llega a hibridizarse,
$(1,4,6)$. Se recomienda extremar las prácticas de higiene en estos lugares. El tratamiento con alcohol sobre camas o ropas, etc. al aire libre no tiene efectividad, ya que éste no posee acción residual.

La ausencia de signos clínicos espectaculares tales como convulsiones, vómitos, irritabilidad, úlceras, etc., a corto o mediano plazo, en ningún caso son garantía de inocuidad de un plaguicida, por más efectivo que éste haya sido en el control de la pediculosis o de otros parásitos.

La OMS, 1981, ha recopilado los riesgos toxicológicos del DDT o sus derivados en salud pública $(9,11,12)$, y se conocen los daños causados en los ecosistemas biológicos (14), por lo cual estos productos deben excluirse en el control de la pediculosis en humanos, según los criterios de ética médica, expuestos en la XV sección del consejo de la Organización Internacional de las Ciencias Médicas (Manila, Filipinas, septiembre de 1981). Esto obliga a las entidades encargadas de la salud pública a restringir el uso de plaguicidas y a recomendar su empleo sólo por personal altamente especializado $(17,29-31)$.

El reconocimiento del poder insecticida del alcohol de bebida nos recuerda que dicha acción es causa directa de su toxicidad, fenómeno ya bien estudiado en otros modelos biológicos, tales como su poder teratogénico en ranas (19), neurotoxicidad en roedores $(20,21,23,24,26)$, y en humanos $(10,23)$, daño inmunológico $(22)$, alteraciones genéticas en Drosophila (25), y en ratones (32), etc.

Los alcoholes de bebida son considerados drogas psicotóxicas y dado el riesgo al usarlos de inducir drogadicción en individuos predispuestos $(10,32)$, este tratamiento nunca debe generalizarse como repelente ni preventivo de la pediculosis. Hasta la presente publicación, este es el método de más alta eficiencia para la pediculosis en humanos con mínimos riesgos toxicológicos.

\section{Advertencias}

Dada la heterogeneidad química de los productos alcohólicos industriales y de bebida (aguardiente), es necesario seguir las siguientes precauciones: 
1. Cerciorarse de que el aguardiente o bebida alcohólica sea de buena calidad con el grado alcohólico entre 30 a 50 grados.

2. No fumar o prender llamas con fósforos, etc. durante la aplicación. Los vapores de alcohol podrían incendiarse y causar quemaduras al paciente.

3. No hacer mezclas de aguardiente con otras sustancias químicas ni mucho menos con plaguicidas usados en agricultura o en ganadería.

4. Nunca tratar de reemplazar el aguardiente por alcohol industrial.

5. Consultar antes con un farmaceuta, enfermera, médico o familiar si al paciente le hace daño el aguardiente.

6. No dejar que los niños solos usen el aguardiente para bañarse la cabeza.

7. No abandonar niños (infantes) durante la aplicación, ya que la bolsa plástica, si no está bien asegurada, puede caer sobre la cara e impedir la respiración del niño.

\section{Agradecimientos}

Se agradece la colaboración del personal de la escuela de la vereda de LaBalsa, Bertha Hernández de Ospina, Chía, Cundinamarca, por la cooperación prestada en algunas de las prácticas. A la Facultad de Enfermería de la Universidad Nacional, en especial a las profesoras del Departamento de Salud Pública, por su apoyo y colaboración al utilizar esta metodología en sus prácticas docentes y de investigación. Al doctor Carlos Ramírez C. por la corrección del manuscrito.

\section{Referencias}

1. Faust EC, P Ch Beaver and R C Jung. Animal agents and vector of human disease; Ed. Lea and Febiger, Philadelphia, 1968; 347.

2. OPS. Control de las enfermedades trasmisibles en el hombre, Ed. As Bebeson. Publicación Cientifica No. 372. $1978 ; 146$.

3. Shepard, HH. The chemistry and action of insecticides; Ed. McGraw-Hill Co. New York: 1951; 303.

4. Brumpt L, V Brumpt. Parasitología prática; Ed. Toroy-Masson SA Barcelona: 1969; 74.

5. Chandler AC, Read CP. Introduction to parasitology; 10th Edition, Ed. John Willey and Son, New York: 1962; 617.
6. Leclereg M. Entomological parasitology; Ed. Pergamon Press. London: 2969;14.

7. Wigglesworth VB. Fisiología de los insectos; Ed. Acriba Zaragoza, España 1974; 14.

8. Weidhaas DE, NG Gratz. Piojos, WHO/NBC 1982; $82: 858,10$.

9. Haymarker E, Ginzler, AM. The toxic effects of prolonged ingestion of DDT in dogs with special reference to lesions in the brain. Am J Med Sci 1946;212:423.

10. Goodwin D. Genetic component of alcoholism. Ann Rev Med 1981;32:93.

11. Morgan DP Roan CC. The metabolism of DDT in man A Toxicol 1974; 12: 39.

12. OMS. DDT y sus derivados; criterios de salud ambiental. Publicación científica.1982; 425:211.

13. Paul V, et al. Evidence for a hazardous interaction between ethanol and the insecticides Endosulfan in rats Pharmacol Toxicol 1992; 70: 268.

14. Peakall DR. Pesticides and the reproduction of birds; Scientific American 1951; 222 : 73.

15. Vilaseca C. Las plagas de nunca acabar: los piojos; ser padres, 1982; 8: 42.

16. Norris DM, Baker JM. Nutrition of Xyleborus ferrugineus: I: Ethanol in diets as tunneling, (feeding) stimulant Ann Ent Soc Am 1969; 62:592.

17. Gutteridge F. Experimentación con seres humanos y ética médica. Crónica de la OMS 1981; 35:233.

18. Cicero Th. Neuroendocrinodogical effects of alcohol Ann Rev Med 1981; 32: 123.

19. Dresser TH et al. Teratogenic assesment of four solvents using the frog embryo teratogenic asseyXenopus, (FETAX). J Appl Toxicol 1992; 12:49.

20. Goldstein DB, Chin JH, Lyon RC. Ethanol disordering of spin-labelled mouse brain membranes. Correlation with genetically determined ethanol sensitivity of mice. Proc Natl Acad Sci 1982; 79: 4231.

21. Hinson WG, et al. Nuclear protein phosphorilation in rat cerebral cells following acute exposure to ethanol. Appl Theor Electrophor 1991; 2:93.

22. Jayasinghe R, Gianutsos G, Hubbard AK. Ethanol induced suppression of cell mediated immunity in the mouse. Alcohol Clini Exp Res 1992;16 : 331 .

23. Matti H, M Kaste. Ethanol intoxication: risk-factor for ischemic brain infartion in adolecent and young adults; Stroke 1981; 12: 422.

24. Mihailescui I, Mohora M, Dinu V. Preliminary evidence for lipid peroxidation and changes in peroxidation status in brain tissue and bloo1d in ethanol intoxicated rats. Rev Roum Physiol 1991; 28:133.

25. Rey M, Palermo AM, Muñoz ER. Nondisjuction induced by ethanol in Drosophila melanogaster females Mut Res 1992; 268:95.

26. RomerTP, Mathiessen ME. Ethanol-induced changes of granular endoplasmic reticulum in hepatocytes of mini-pig foetuses. Acta Path Microbiol Immunol Scan. 1983; 91:413 
27. Goldstein DB. The effects of drugs on membrane fluidity Ann Rev Pharmacol Toxicol 1984; 24: 43.

28. May ML. Insect thermoregulation Ann Rev Entomol 1979; 24: 313.

29. Shirasu Yetal.Mutagenecity screening studies on pesticides in enviromental mutagenesis and carcinogenesis; 6th International Conference Enviromental Mutagenesis.Yokyo Mishima Kyoto, Sept. 21 - 27: Ed. University Tokyo Press, Tokyo 1981; 331.
30. OPS. Lindano, en: Información Farmacológica; Bol OSP. 1985; $94: 85$.

31. OPS. Alcanfor. En: Información Farmacológica; Bol. OSP, 1985; 94:370.

32. Sulik KK, Johnston MC, Webb MA. Fetal alcoholic syndrome. Embriogenesis in a man model; Science 1981; 214:936. 